\title{
Research Corrigenda
}

\section{Pigs expressing salivary phytase produce low-phosphorus manure}

Serguei P. Golovan, Roy G. Meidinger, Ayodele Ajakaiye, Michael Cottrill, Miles Z. Wiederkehr, David J. Barney, Claire Plante, John W. Pollard, Ming Z. Fan, M. Anthony Hayes, Jesper Laursen, J. Peter Hjorth, Roger R. Hacker, John P. Phillips, and Cecil W. Forsberg Nat. Biotechnol. 19, 741-745 (2001).

In the Discussion, p. 744, the authors made an incorrect comparison. The sentence

"The reduction in fecal phosphorus of $64-67 \%$ by finisher phytase pigs not receiving the supplemental phosphate substantially exceeds the $40 \%$ reduction reported for finisher pigs fed expensive phytase supplements $(2,500 \mathrm{U} / \mathrm{kg} \text { feed })^{31}$."

should be replaced with the following:

"The reduction in fecal phosphorus of $64-67 \%$ by finisher phytase pigs not receiving supplemental phosphate substantially exceeded the $43 \%$ and 35\% reductions previously reported for grower and finisher pigs receiving 1,000 U of phytase per $\mathrm{kg}$ of feed (refs 34,35 ), a concentration of phytase in the range of that recommended for addition to swine diets ${ }^{5}$."

The authors regret the error. 